* Docente da Universidade do Porto (Portugal). Mestre em Direito (Integração Europeia) pela Universidade de Coimbra (Portugal). E-mail: altinarento (a) gmail.com

** Inspectora Superior Principal da Polícia de Segurança Pública (Portugal). Auditora de Defesa Nacional (Portugal). Licenciada em Direito pela Universidade de Lisboa (Portugal). E-mail: altinarento@gmail.com

\section{Poderá o "Espaço Schengen" europeu servir como uma espécie de "Laboratório de Análise" para o Mercosul?}

\section{Can the european "Schengen Area" Fit out EVENTUALLY AS A SORT OF ${ }^{6}$ LABORATORY OF Analysis" FOR Mercosur?}

\author{
Abel Laureano * \\ Altina Rento **
}

Resumo: O presente estudo constitui um ensaio sobre a eventual viabilidade teórica da transponibilidade, para o seio da experiência vivencial do Mercosul, do chamado "Espaço Schengen" europeu. Principia-se, após alguns considerandos preliminares, por um pequeno esboço comparativo entre a União Europeia (com a qual se identifica basicamente, na actualidade, o "Espaço Schengen") e o Mercosul. Segue-se um conciso volver de olhos à origem e ao desenvolvimento do "Espaço Schengen", a fim de se perceber qual a respectiva filosofia enformadora e o rumo mediante o qual aquela se materializou. E termina-se com uma curta dissecação dos factores decisivos conducentes ao fornecimento duma resposta à interrogação inicialmente colocada.

Palavras-Chave: Mercosul. União Europeia. "Espaço Schengen".

Abstract: The present study is an essay on the possible theoretical feasibility of the transferability, to the living experience of Mercosur, of the so-called European "Schengen Area". Firstly, after some preliminary notes, we begin with a small comparative sketch between the European Union (with which the "Schengen Area" basically identifies today) and the Mercosur. The following is a concise look at the origin and development of the "Schengen Area", in order to understand its main philosophy and the way by which it has been materialized. And this study ends with a short dissection of the decisive elements conducive to providing an answer to the initially posed query.

Keywords: Mercosur. European Union. "Schengen Area". 


\section{INTRODUÇÃO}

O processo de integração europeia, pioneiro no Mundo, iniciou-se já há mais de sessenta anos. Uma das mais curiosas experiências que se lhe seguiu, algumas décadas mais tarde, foi a do Mercosul. Esta última, como é sabido, inspirou-se no modelo europeu, embora apontando, no seu quadro inicial, para objectivos últimos mais circunscritos. Dito doutro modo, e especificando, nos mentores da criação do Mercosul perfilava-se, como objectivo a atingir, o da consecução dum mercado comum ente os respectivos Estados-Partes. Numa teoria clássica da integração económica internacional, a forma (ou fase) do mercado comum situa-se como que "a meio da tabela", seguindo-se à (ou sendo imediatamente mais complexa do que a) união aduaneira, e antecedendo (ou sendo imediatamente menos complexa do que a) união económica.

É verosímil extrair, da análise do pensamento dos mentores da integração europeia e diferentemente do sucedido quanto ao Mercosul, a intenção de abrir a porta, por tal meio, a uma dinâmica que poderia conduzir, numa natural e lógica conclusão, à união económica e monetária, forma (ou fase) última da referida clássica visão da integração económica internacional. E mais: não estaria sequer excluída do quadro da integração europeia, antes podia descortinar-se como uma lógica consequência daquele último patamar, a verosimilhança de vir a desembocar-se numa integração política, com a criação duma nova entidade que, no futuro, se sobreporia, como unidade englobante, aos respectivos EstadosMembros.

O processo de integração sul-americana do Mercosul apresenta-se pois, no comparativo com o processo de integração europeia (cuja primeira grande manifestação ou materialização foi a Comunidade Económica Europeia, embora cronologicamente algo posterior à pioneira Comunidade Europeia do Carvão e do Aço), como um processo mais cauto, talvez menos ambicioso mas quiçá mais realista. Não será estranha a esta circunstância o facto de o Mercosul ter arrancado em inícios da década de noventa, quando o processo europeu de integração levava mais de três décadas de existência, marcada, na respectiva evolução, por alguns altos e baixos.

Seja como for, a prudência dos mentores do Mercosul conduziu-os a tomar, como modelo já testado e razoavelmente positivo, o figurino da Comunidade Europeia, o que lhes permitiu beneficiar da experiência dos Europeus, oferecendo-lhes simultaneamente a possibilidade de não incorrerem em erros com que os precursores Europeus se viram confrontados. 


\section{UM BREVE TRAÇADO GENÉRICO COMPARATIVO ENTRE A UNIÃO EUROPEIA E O MERCOSUL}

I. A opção mercosuriana afigurava-se bastante sensata, até porque a experiência europeia e a experiência sul-americana ostentavam diferenças e semelhanças.

Começando pelas primeiras, é de salientar que o processo de integração europeia nasceu no rescaldo da mais sangrenta Guerra Mundial desde sempre vista. Os horrores da guerra, bem presentes no corpo e no espírito dos "Pais Fundadores" da Europa Integrada, levaram-nos, compreensivelmente, a encarar como desejável uma construção que impedisse definitivamente o deflagrar dum novo e semelhante conflito no território europeu (sublinhe-se que a Segunda Guerra Mundial foi, em rigor, uma guerra europeia que acabou por estender-se ao resto do Mundo). Bem se entende, nessa ordem de ideias, que procurassem gizar um mecanismo à altura dum tal desafio, vale dizer, um mecanismo ousado que pudesse, dum modo efectivo, "amarrar" entre si os Estados Europeus de tal maneira, que o espectro dum novo conflito militar entre eles se tornasse virtualmente impossível. Isso implicava a edificação duma estrutura ambiciosa, capaz de conter nas suas malhas toda a (ainda mal contida) agressividade e energia negativa, à solta numa Europa recém-devastada.

Nada de tão grave esteve, felizmente, na génese do Mercosul. É certo que os Estados da América do Sul são menos homogéneos, entre si, do que normalmente parecem aos olhos dos Europeus. Mas tal heterogeneidade nunca chegou a atingir dimensões e consequências de tão amplo calibre, como aquelas que arrasaram a Europa em meados do Séc. XX. Assim se percebe que também não tenha sido sentida como tão instante ou necessária a congeminação duma mais complexa arquitectura de integração.

Ainda quanto a diferenças, é de salientar que as Economias europeias apresentam índices superiores de desenvolvimento e maturidade, o que naturalmente conduziu os Sul-Americanos a olharem com atenção as passadas dos Europeus; na verdade, os respectivos graus de sofisticação económicopolítica eram diferentes, pendendo a balança em favor dos Europeus. Mesmo no momento presente, de resto, em que se atravessa, na Europa, uma dolorosa e profunda crise, as conformações estruturais e o próprio nível de desenvolvimento europeu continuam a manter o restante Mundo de olhos postos neste Continente, como um dos grandes expoentes da vida contemporânea. 
Mas outras diferenças apartam Europeus e Sul-Americanos, não sendo as menores delas as disparidades linguísticas: ao passo que a Europa é uma autêntica "manta de retalhos" de línguas (factor que torna a comunicação directa entre Europeus particularmente difícil, levando a naturais sensações de estraneidade), a comunicação entre os Sul-Americanos é muito mais fácil, pois a América do Sul é palco de somente duas grandes línguas oficiais, o português e o espanhol, para além de estas bastante semelhantes entre si. Assim, quer relativamente às facilidades de entendimento entre os Povos, quer quanto aos problemas logísticos derivados do multilinguismo, são incomparavelmente menos complicadas as questões quotidianamente enfrentadas pelos Sul-Americanos; isto, sem esquecer o grande papel que a língua desempenha como elo de aproximação (e não só de mera comunicação) entre os Povos, já que se torna evidentemente mais difícil tecer laços de proximidade entre seres humanos que nem sequer se entendam ao falar.

Continuando com o rol de diferenças, uma outra fundamental distinção deve ser evidenciada: trata-se da temática dos espaços territoriais. Na verdade, ao passo que, entre os Estados-Membros da União Europeia, e pese embora a existência de diferenças de dimensão das respectivas áreas territoriais (podendo distinguir-se, grosso modo, entre Estados-Membros grandes, médios e pequenos), não se vislumbram assimetrias territoriais que ultrapassem uma certa monta. Diversamente sucedem as coisas no tocante aos Estados-Partes do Mercosul, onde se encontra um Estado "gigante" (o Brasil), um "super-grande" (a Argentina), um "grande" (a Venezuela) e dois "pequenos" (o Uruguai e o Paraguai $)^{1}$; o gigantismo do Brasil torna-o claramente predominante no contexto do Mercosul, marcando o compasso do ritmo de integração desta Organização Internacional; de facto, e sem menosprezo dos restantes, designadamente da Argentina, são os interesses do Brasil os prevalecentes: o que significa, afinal e em derradeira análise, que a integração sul-americana do Mercosul está, em boa parte, cativa das orientações ditadas pelas conveniências da política interna e externa brasileira; ora, se esta circunstância torna simultaneamente menos laboriosa a obtenção de consensos (pois é virtualmente impossível, em termos práticos, levar a cabo alguma actividade ou tomar alguma posição, por banda do Mercosul, caso o Brasil não dê o seu impulso ou, pelo menos, o seu

\footnotetext{
${ }^{1}$ O Mercosul foi abalado recentemente por uma contenda envolvendo o Paraguai e a Venezuela; não sendo este o local adequado para o debate sobre tal problemática, consideramos ambos aqueles Estados, para efeitos expositivos, como sendo presentemente Estados-Partes do Mercosul. Na verdade, a posição que possa tomar-se sobre a questão, em termos jurídicos, não afecta substancialmente o fio do nosso discurso, pelo que omitiremos desenvolvimentos sobre o ponto.
} 
assentimento), verdade é, por outro lado, que a marcha da integração mercosuriana se torna mais imprevisível e tendencialmente menos “equilibrada”.

II. Por outro lado, as semelhanças existentes entre a Europa e a América do Sul contribuem para explicar em boa parcela o modelo de integração sulamericana do Mercosul.

Desde logo, pode lobrigar-se um paralelismo estrutural relativamente à existência dum eixo central que serve de âncora a ambos os processos de integração: ao eixo franco-alemão, Estados cuja reconciliação esteve na base do empreendimento da União Europeia, pode contrapor-se o eixo argentinobrasileiro (PATRÍCIO, 2007), Estados cuja colaboração veio a viabilizar o surgimento e a manutenção do Mercosul.

De outra banda, a experiência do Mercosul nasce num contexto de escolha, por parte dos respectivos Estados-Partes, do modelo da economia de mercado, o qual também fundou a estruturação económica da integração europeia.

De resto, o caminho percorrido por ambos os processos de integração é, dalgum modo, o mesmo: uma zona de comércio livre e uma união aduaneira, ambas já concretizadas por Europeus e (embora ainda com algumas lacunas) pelos Sul-Americanos; e um mercado comum, já atingido (todavia com certas incompletudes) pelos Europeus e ainda somente posto como meta pelos SulAmericanos. Importa efectivamente reconhecer em abono da verdade, que, em rigor e apesar de já terem atingido a fase da união económica e monetária, nem os próprios Europeus conseguiram ainda edificar um perfeito mercado comum, atenta a persistência de certas barreiras físicas, técnicas e fiscais à livre circulação no interior do espaço da União Europeia; seja como for, é inegável o maior avanço dos Europeus, neste campo, o que de resto não é de espantar, bastando ter em conta que a integração europeia se iniciou cerca de quarenta anos mais cedo (a Comunidade Europeia do Carvão e do Aço, primeira materialização do projecto europeu, foi fundada pelo Tratado de Paris de 1951, ao passo que o Mercosul foi fundado pelo Tratado de Assunção de 1991).

Mas as semelhanças entre Europeus e Sul-Americanos não se quedam por aqui. Existem laços civilizacionais fortes e duradouros entre ambos os Continentes, já que a população predominante da América do Sul (como, aliás, a de toda a América em geral) é a resultante dum movimento colonizador europeu. O modo sul-americano de "estar no mundo" resulta, pois, duma afinidade atribuível a laços de sangue e à moldagem civilizacional da "Velha Europa". 


\section{GÊNESE E EVOLUÇÃO ESQUEMÁTICA DO "ESPAÇO SCHENGEN" EUROPEU}

I. Chegados a este ponto do nosso ensaio, é altura de explicar, em palavras breves mas com a exequível profundidade, por que razão surgiu o "Espaço Schengen" europeu, qual a sua evolução e as suas principais características.

Logo no Tratado Institutivo da Comunidade Económica Europeia, datado de 1957 e fundador da mais importante das Comunidades Europeias, se previu uma calendarização precisa para o estabelecimento do mercado comum (aquele Tratado preceituava, no respectivo articulado, que o mercado comum seria "progressivamente estabelecido ao longo de um período de transição de doze anos"). Ora, como pode ler-se num célebre e clássico acórdão do Tribunal de Justiça europeu, o conceito de mercado comum, "elaborado em jurisprudência constante do Tribunal, visa a eliminação de todos os obstáculos às trocas intracomunitárias a fim de fundir os mercados nacionais num mercado único o mais possível idêntico a um verdadeiro e próprio mercado interno" (COMUNIDADES EUROPEIAS, 1982).

Esta forma (ou fase) da integração económica internacional consubstancia-se portanto no seu âmago, tradicionalmente, como corporizando um mercado único no respectivo espaço de integração. É certo que vem a surgir mais tarde, no seio da União Europeia, a nova referência à figura dum mercado interno, substitutivo da alusão a um mercado comum, e cuja ideia basilar é a da plena interpenetração de todo o espaço comunitário, mediante a concomitante inexistência de quaisquer estrangulamentos que se lhe oponham: com efeito, a essência do conceito de mercado interno reside na total interpenetração do espaço da União através da eliminação das suas fronteiras internas, ou seja, das fronteiras separadoras dos Estados-Membros entre si, como reza o art. $26^{\circ}, \mathrm{n}^{\circ} 2$ do Tratado sobre o Funcionamento da União Europeia (TFUE). E tal linha de rumo constitui uma componente fulcral do edifício comunitário, pois, segundo a clássica jurisprudência comunitária, os preceitos do Tratado "relativos à livre circulação das mercadorias, das pessoas, dos serviços e dos capitais constituem disposições fundamentais para a Comunidade sendo proibido todo e qualquer entrave, ainda que de somenos importância, a esta liberdade" (COMUNIDADES EUROPEIAS, 1989).

Contudo, em nossa opinião, não existe qualquer diferença teórica de relevo, subjacente à substituição da expressão "mercado comum" pela expressão "mercado interno"; temos por certo que a mudança linguística da primeira locução 
para a segunda, operada a dada altura na lei fundamental da União Europeia, teve basicamente um intuito "cosmético", por assim dizer. Conscientes de que fora ultrapassado o prazo fixado para a consecução do mercado comum, os dirigentes da União Europeia resolveram proceder a uma nova calendarização encapotada. $\mathrm{Na}$ verdade, os testemunhos anteriormente arrolados parecem revelar bem que a substância da realidade descrita se mantém, pois, do que se trata, é sempre da transformação de vários mercados nacionais num mercado único, através da abolição de obstáculos à liberdade de circulação no interior do espaço integrado: no fundo, os Estados-Membros acordaram, a certa altura, em lançar uma ofensiva contra as barreiras ainda existentes, de modo a que viesse efectivamente a alcançar-se uma situação de absoluta liberdade de circulação intracomunitária, o que deveria progressivamente acontecer até 31 de Dezembro de 1992 (o que de novo, aliás, se não verificou). A supramencionada mudança terminológica terá tido a ver, portanto e tão-somente, com razões de "imagem" política, não valendo a pena, assim, insistir mais na dita alteração vocabular.

II. Fixemo-nos pois no plano da substância, para nos interrogarmos sobre se o expediente europeu de Schengen, inserido na tentativa de consecução dum mercado único, pode, ou não, ser utilmente inspirador para a sequência do trilho do Mercosul.

A iniciativa de Schengen ocorreu no meio da década de oitenta, numa altura em que a integração europeia se debatia com um clima de europessimismo, sequente às graves perturbações causadas aos países europeus pelo chamado Primeiro Choque Petrolífero. Este, que apanhou a Europa desprevenida, traduziuse numa alta brusca e generalizada dos preços do petróleo no mercado mundial, ocorrida perto de meados da década de setenta e abalando fortemente as Economias dos países da Europa Ocidental, fracos em recursos petrolíferos e, por isso, "importadores" forçados da inflação induzida pela mencionada subida de preços. Retomando hábitos tradicionais e sob pressão dos respectivos eleitorados, os dirigentes dos Estados-Membros da Comunidade Europeia viraram-se precipuamente para a busca de soluções individuais de combate à Crise, o que levou a um arrefecimento do processo de integração europeia.

No entanto, algum desalento com a (escassa) eficácia das medidas puramente nacionais para lidar com um fenómeno de tal envergadura, bem como algum "alívio" posterior aos impactos iniciais da Crise, levaram alguns Estados-Membros a uma alteração de postura. 
É assim que, em 1985, a Alemanha, a França, a Bélgica, os Países Baixos e o Luxemburgo, Estados do "coração" da Europa Comunitária, resolveram dar novo fôlego à colaboração no seio europeu, mediante um estádio superior de materialização das liberdades de circulação, celebrando entre si o Acordo de Schengen (de seu nome oficial "Acordo entre os Governos dos Estados da União Económica Benelux, da República Federal da Alemanha e da República Francesa Relativo à Supressão Gradual dos Controlos nas Fronteiras Comuns"). Em sequência do referido compromisso internacional, os mesmos Estados vieram a celebrar entre si, em 1990, a Convenção de Schengen (oficialmente designada "Convenção de Aplicação do Acordo de Schengen de 14 de Junho de 1985 entre os Governos dos Estados da União Económica Benelux, da República Federal da Alemanha e da República Francesa Relativo à Supressão Gradual dos Controlos nas Fronteiras Comuns").

Ambas estas démarches surgiram à margem do processo de integração europeia. Mas o posterior Tratado de Amesterdão, assinado em 2 de Outubro de 1997 e entrado em vigor em 1 de Maio de 1999, que reviu o quadro jurídico fundamental da União Europeia, veio incorporar o acervo de Schengen no tecido jurídico da União. E, dentro da mesma senda, o Tratado de Lisboa, assinado em 13 de Dezembro de 2007 e entrado em vigor em 1 de Dezembro de 2009, que introduziu o traçado mais recente do regime jurídico fundamental da União Europeia, manteve o essencial do conteúdo de Schengen, "comunitarizando-o" e passando a contê-lo, sob o título de "espaço de liberdade, segurança e justiça", nos arts. $67^{\circ}$ a $89^{\circ}$ do TFUE.

Vista assim muito sumariamente a génese e evolução do "Espaço Schengen", cumpre ainda fazer um reparo: é que aquele Espaço não se identifica rigorosamente com o "espaço de liberdade, segurança e justiça" do TFUE, dado que não abrange certos Estados-Membros da União Europeia², englobando, em contrapartida, certos outros Estados não pertencentes à União Europeia ${ }^{3}$. Mas não nos alongaremos neste tópico, uma vez que, na sua vasta maioria, existe uma coincidência entre ambas as realidades (o que permite de resto um aligeiramento da exposição, desembaraçando-a de dispensáveis preciosismos).

\footnotetext{
${ }^{2}$ Casos do Reino Unido e da Irlanda (embora vinculados pelas normas do mercado interno da União), da Bulgária e da Roménia (com início de participação ainda suspenso), da Croácia (membro muito recente da União e com participação efectiva prevista para um futuro relativamente próximo), e de Chipre (devido à sua divisão interna). Por seu turno, a Dinamarca é membro da União e do "Espaço Schengen", gozando porém dum regime especial, podendo ir procedendo a auto-exclusões, por força do estatuído no Protocolo ( $\mathrm{n}^{\circ}$ 22) Relativo à Posição da Dinamarca anexo ao Tratado de Lisboa. ${ }^{3}$ Casos da Noruega, da Islândia e da Suíça, por razões de fundo não coincidentes, mas cuja explanação não se insere nos propósitos e na dimensão do presente estudo.
} 
III. Convém agora observar brevemente, embora com a possível proximidade, quais são as traves-mestras do conteúdo do "Espaço Schengen"; e a primeira grande nota a salientar é a de que as grandes linhas estruturantes do "Espaço Schengen" se mantiveram intocadas desde os seus inícios. O que se tinha basicamente em vista, e se continua a ter, é contribuir para a materialização da ideia dum mercado único, eliminando os controlos fronteiriços no interior da respectiva zona (vale dizer, entre os Estados participantes no dito "Espaço"); por outras palavras, visava-se abolir os controlos nas denomináveis fronteiras internas. O território conjunto formado pelas áreas territoriais daqueles Estados tem por sua vez, naturalmente, fronteiras com o resto do Mundo, as denomináveis fronteiras externas (correspondentes, afinal, ao somatório das fronteiras nacionais que delimitam simultaneamente o próprio "Espaço Schengen"), constituindo aquelas objecto dos procedimentos de controlo fronteiriço. Deste modo se desembaraça a circulação no interior do "Espaço", contribuindo para a efectivação prática da directriz da liberdade de circulação, enquanto raiz e fundamento último de toda a exposta construção.

Como facilmente se intui, estas guias directoras requerem uma série de medidas concretas, para se tornarem viáveis: é que, para além da liberdade, impõe-se assegurar no interior do "Espaço", com idêntico nível de prioridade, a manutenção dum adequado grau de segurança, cuja consecução passa por diversos factores.

Na actual configuração do "Espaço Schengen" contida na regulamentação do "espaço de liberdade, segurança e justiça" da União Europeia abrangem-se, assim, para além dos essenciais controlos das fronteiras externas e da essencial supressão dos controlos nas fronteiras internas desse espaço, e naturalmente ligados com tais temáticas, vários pontos específicos, cuja tessitura jurídica determina os termos da operacionalização do funcionamento do mencionado "Espaço" e reflecte o influxo das preocupações acima enunciadas. São questões como a da atribuição de vistos, da concessão de asilo, do estatuto dos refugiados, da elaboração duma lista de pessoas indicadas para efeitos de não admissão no espaço, da cooperação policial e da feitura e manutenção dum sistema de informações.

Fornecendo uma panorâmica sumária, consignamos que as normas delineadoras do "espaço de liberdade, segurança e justiça" da União Europeia se desdobram por alguns capítulos, cujas epígrafes nos elucidam razoavelmente sobre o fundamental dos respectivos conteúdos e às quais nos cingiremos: o Cap. I ("Disposições Gerais"), o Cap. II ("Políticas relativas aos Controlos nas 
Fronteiras, ao Asilo e à Imigração"), o Cap. III (“Cooperação Judiciária em Matéria Civil”), o Cap. IV (“Cooperação Judiciária em Matéria Penal”) e o Cap. V ("Cooperação Policial”).

\section{SERÁ EQUACIONÁVEL UMA "TRANSPONIBILIDADE" DA EXPERIÊNCIA DO "ESPAÇO SCHENGEN" PARA O ÂMBITO DO MERCOSUL?}

Sobra, finalmente, a magna pergunta: seria teoricamente aconselhável, ou desaconselhável, uma "transposição" do mecanismo do "Espaço Schengen" para o âmbito do Mercosul? É finalmente tempo de responder, considerando tudo o exposto e aduzindo os pertinentes considerandos alusivos ao Mercosul, à interrogação balizadora da presente investigação.

Manda a boa metodologia que, já à cabeça, acrescentemos dois apontamentos básicos. O primeiro apontamento é o de que o "Espaço Schengen" tem cumprido razoavelmente os objectivos para os quais foi ideado, agilizando a liberdade de circulação no seu interior, sem notório prejuízo para a garantia da segurança dos respectivos Estados. Em segundo apontamento deve notar-se, todavia, que o funcionamento do "Espaço Schengen" não tem sido isento de dificuldades, as quais sofreram um agravamento nos tempos mais recentes. Estes apontamentos vão, de resto, entreabrir-nos a porta para compreender quais as falhas que têm vindo a pressionar este empreendimento, o que contribuirá para aprimorar os termos da resposta final à interrogação de base do nosso ensaio. Quais são então, feitas as contas e em balanço, os ingredientes que importa focalizar, em ordem a habilitar-nos com os elementos necessários para um juízo sobre a desejabilidade, ou não, do lançamento duma experiência paralela à do "Espaço Schengen", no âmbito do Mercosul?

Sem querermos preocupar-nos com o alinhamento da nossa exposição por um estrito padrão de hierarquizações, começamos por aludir ao ingrediente da confiança que um empreendimento, como o "Espaço Schengen", requer entre os Estados envolvidos no mesmo. O facto de um Estado se encontrar obrigado a deixar circular livremente pelo seu território, sem qualquer espécie de sistemático controlo fronteiriço, pessoas e bens provenientes dum outro Estado, significa afinal que o primeiro fica na inteira dependência deste último Estado; o que, em última análise, significa enfim que todos os Estados desse "Espaço" ficam na dependência dos Estados cujas fronteiras (ou porções de fronteira) são, simultaneamente, componentes da fronteira externa comum do 
"Espaço". Ora, não se trata duma realidade fácil de atingir, como o vieram demonstrar as fortes dificuldades com que o "Espaço Schengen" se vem debatendo ultimamente e das quais deixamos, a título de exemplo: os problemas, ocorridos na sequência de efeitos laterais da chamada "Primavera Árabe", que opuseram a Itália à França, apontados por Pascouau (2011a, 2011b) e Zaiotti (2011); a desconfiança que alguns Estados-Membros do "Espaço Schengen" (designadamente do Centro da Europa) têm publicamente revelado em relação a outros, como a Roménia ou a Bulgária, cuja entrada para o "Espaço" se encontra, de facto, ainda suspensa - salientam-se, no grupo dos "não confiantes", a Alemanha e a França, apoiados nessa visão das coisas pela Áustria, Dinamarca, Suécia e Suíça; alegam-se, na raiz dessa posição, questões de corrupção e fortes influências políticas do crime transnacional organizado (PARKES, 2011, p. 2); e ainda o particular caso da Grécia, mais grave por este Estado fazer parte do "Espaço Schengen" e haver séria desconfiança quanto à sua capacidade de zelar eficazmente pela preservação da respectiva porção da fronteira externa comum do "Espaço" - havendo mesmo quem julgue que a Grécia representa um sério risco para a própria viabilidade do "Espaço Schengen", como Brady (2012, p. 1, 18-22), merecendo realce o facto de que a situação da Grécia se tem agravado recentemente, devido aos estrangulamentos financeiros públicos de que tem sido objecto. Ora, o que dizer do ingrediente da confiança, no concernente ao Mercosul? Tem sido reportado existirem entre os Estados-Partes do Mercosul diferenças, e mesmo antagonismos, assinaláveis, nomeadamente resultantes de lutas e conflitos sequentes aos processos de independência e ainda não completamente ultrapassados (WOLKMER, 1998, p. 45); trata-se naturalmente dum factor desencorajador que, todavia, não impediu o surgimento dum processo de integração tão interessante como é o Mercosul; pelo que, apesar de perturbador, não deverá considerar-se, a nosso ver, como taxativamente impeditivo duma "réplica" sulamericana do "Espaço Schengen".

Torna-se evidente, por outro lado, que uma realidade com as características do "Espaço Schengen" é incompatível com um disseminado e forte ambiente de nacionalismos, até porque as questões ou conflitos de fronteiras, que representam manifestações de agressividades nacionalistas, bolem directamente com o cerne dum empreendimento que visa, precisamente, a eliminação de obstáculos ao atravessamento de fronteiras. É sabido que, no seio da União Europeia, existem movimentos nacionalistas, até porque o sistema político democrático admite a sua existência, dentro de certos limites e no 
exercício da chamada liberdade de expressão e de acção política. É pois decisivo, aqui, um elemento de grau, sendo certo que tais ideias e movimentos não têm obstado, no seio do "Espaço Schengen", à existência e prosseguimento deste. O Mercosul tem-se ressentido deste tipo de questões, não faltando mesmo alguns sentimentos nacionalistas bastante vincados (PIZZOLO, 2002, p. 278); para o exercício teórico que nos ocupa, o freio representado por tais fenómenos dependerá, naturalmente, da dimensão de que se forem revestindo; não cremos que, tal como actualmente se configuram, tivessem poder para contrariar o lançamento e a subsistência duma eventual iniciativa semelhante ao "Espaço Schengen".

Também se revela crucial a existência, nos Estados envolvidos num empreendimento como o "Espaço Schengen", duma certa estabilidade política dos Estados participantes. Porque a decisão da abertura de fronteiras implica uma série de importantes consequências, é imprescindível que tal decisão não possa ser inopinadamente posta em causa pela mudança dos Governos dos respectivos Estados, já que tais alterações fazem parte duma normal alternância democrática, havendo naturalmente de contar-se com elas como algo de expectável, mas que não ponham em causa as opções de fundo dos respectivos Estados em matérias tão importantes da sua política externa. Também o "Espaço Schengen" tem convivido com esta faceta democrática, sem por isso ter visto interrompida, para além dos naturais dissensos políticos do quotidiano, a sua existência ou marcha. Ora, o Mercosul tem enfermado dum certa instabilidade política, o que tem representado, efectivamente, um obstáculo de monta ao empreendimento da integração (SÁNCHEZ, 2004, p. 71); não significa isso porém, em nosso juízo, que o até agora sucedido constituísse barreira intransponível para se avançar rumo a um projecto idêntico ao do "Espaço Schengen", o qual provavelmente se ressentiria no entanto, tal como vem sucedendo com o próprio Mercosul, de alguns impulsos e hesitações atribuíveis a fenómenos de volatilidade política.

Um outro ingrediente que, na actualidade, se apresenta como capital, é o nível de capacidade económica dos Estados envolvidos num empreendimento como o "Espaço Schengen"; tal fica a dever-se à evolução tecnológica dos controlos das fronteiras externas, com as inseparáveis sofisticações dos instrumentos de controlo e as inerentes necessidades de investimento no recrutamento e na formação de qualificados agentes fiscalizadores. Também neste ponto surgem algumas dúvidas quanto ao Mercosul, por este sofrer de alguma debilidade económica (FRERES; SANAHUJA, 2006, p. 36); quanto 
a nós, não se trataria dum travão à possibilidade de avançar para um modelo análogo ao do "Espaço Schengen", mas certamente se reflectiria numa menor sofisticação do modelo a construir (repare-se que já no presente se ressentem daquela circunstância, naturalmente, os controlos das várias fronteiras nacionais).

Releva outrossim, como factor de suma relevância numa área como a do "Espaço Schengen", a verificação duma certa homogeneidade entre os Estados componentes; a existência de disparidades entre os mesmos representa uma fonte de dificuldades, dependendo do respectivo nível de desigualdades um melhor ou um pior funcionamento desse "Espaço". Como sucede, de resto, com o fenómeno geral da integração internacional, a ocorrência de desníveis entre os Estados envolvidos dificulta o nascimento e a adequada manutenção dum fenómeno de abertura de fronteiras externas, atentos os diversos problemas que suscita, nomeadamente no plano da gestão política do funcionamento daquelas fronteiras. Ora, no Mercosul existem apreciáveis assimetrias entre os seus Estados-Partes, nomeadamente bem superiores às que ocorrem no espaço da União Europeia (CEIA, 2008, p. 5), sobressaindo os interesses prevalecentes dos "maiores", e especialmente do Brasil (ALMEIDA, 2000, p. 15); o que conduz, em nossa opinião, a que (tal como aliás aconteceu e acontece no panorama actual, quanto ao Mercosul) dificilmente se formaria, na ausência de vontade política dos "grandes" do Continente Sul-Americano (ou seja, do Brasil e da Argentina), um espaço semelhante ao "Espaço Schengen", quer quanto ao respectivo relevo e implicações práticas na vida internacional geral, quer mesmo quanto a tais realidades na vida quotidiana da maioria dos SulAmericanos.

De fundamental importância para a edificação duma área como o "Espaço Schengen" são, igualmente, as questões financeiras: englobam-se, aqui, temas como o das dotações globais para a construção e funcionamento do sistema, o assunto da repartição de custos entre os intervenientes, a questão dos eventuais Estados "consumidores puros" do sistema, etc.; no "Espaço Schengen", por exemplo, existem Estados que se encontram totalmente dentro do "Espaço", pelo que não têm fronteiras externas (valham os casos do Luxemburgo, da Áustria, da República Checa ou da Suíça). Da problemática do volume das eventuais dotações financeiras, alocáveis para uma iniciativa inspirada no modelo do "Espaço Schengen", já falámos atrás, quando aludimos à maior debilidade económica comparativa da América do Sul; e é provável que, tocantemente a repartições de custos, as respectivas negociações em nada fossem fáceis; o Mercosul beneficia aqui, porém, duma vantagem comparativa, na medida em 
que não existiriam, no seu seio, Estados-Partes que fossem "consumidores puros" dos serviços de controlo das fronteiras externas comuns.

Bastante condicionadoras do funcionamento duma zona como o "Espaço Schengen" são, doutra banda: a natureza das zonas envolventes desse "Espaço", designadamente em termos de estabilidade ou instabilidade política (com óbvios problemas acrescidos para o "Espaço", caso existam zonas confinantes politicamente instáveis); e outrossim a existência, ou não, de pressão migratória para o interior do "Espaço". Quanto ao "Espaço Schengen", pode dizer-se que se verifica, quanto a estas vertentes, um panorama algo sombrio: no tocante a questões de estabilidade política, o Norte de África tem-se revelado, recentemente, como uma área inconstante, sendo que os Estados a Leste do "Espaço Schengen" também não primam pela solidez política (bastando lembrar os casos da Rússia ou da Turquia, para não enumerar mais); pelo que toca a pressões migratórias, elas são muito acentuadas no "Espaço Schengen", destacando-se neste contexto os fluxos migratórios provenientes quer do Norte de África, quer de Estados do Oriente Próximo. Trata-se doutro âmbito no qual o Mercosul gozaria dum benefício comparativo, dado não confinar com zonas de particular instabilidade política, nem com zonas de forte pendor migratório rumo ao seu território; o que facilitaria sobremaneira as coisas, no cotejo com o "Espaço Schengen", pois o controle duma eventual fronteira externa comum exigiria bastante menos cuidados e aparatos logísticos, com tudo o que lhes vem aparelhado.

Resta-nos terminar este enunciado com a alusão a uma severa dificuldade que pode colocar-se a uma área como o "Espaço Schengen": temos em vista eventuais problemas de corrupção, sobretudo quando esta se ache sistematicamente ou preferencialmente ligada ao crime transnacional organizado, e tenha considerável influência política em algum dos Estados que pertença ao grupo dos que partilhem a fronteira externa do "Espaço"; aponta-se estarem nestas circunstâncias, relativamente ao "Espaço Schengen", a Roménia e a Bulgária, embora a sua pertença ao "Espaço" se encontre ainda em suspenso. É de notar que este tipo de fenómenos (corrupção e, sobretudo, corrupção ao mais alto nível) tende a ocorrer em países de menor nível de desenvolvimento económico, o que apontaria para um maior risco comparativo ligado a alguma iniciativa símil ao "Espaço Schengen", oriunda do Mercosul; há todavia um elemento que militaria em sentido oposto, já que os desníveis verificados, entre os Estados limítrofes do Mercosul e esta Organização Internacional, são claramente inferiores a alguns que ocorrem entre estados limítrofes do "Espaço 
Schengen" e este último; seria no entanto um factor a ter em atenta consideração, numa eventual materialização do hipotético "Espaço" aqui congeminado como objecto duma reflexão jurídico-política.

\section{CONCLUSÕES}

Pode equacionar-se duma eventual viabilidade teórica da transponibilidade, para o âmbito do Mercosul, do "Espaço Schengen” europeu.

Apesar de ter começado à margem do processo europeu de integração, o "Espaço Schengen" identifica-se essencialmente, na actualidade, com a União Europeia, dado que a larga maioria dos respectivos Estados componentes são simultaneamente Estados-Membros da União Europeia; isto, para além de o chamado acervo de Schengen ter sido oportunamente integrado na tessitura jurídica da União, onde presentemente figura sob a designação de "espaço de liberdade, segurança e justiça". Dada esta tendencial identificação do "Espaço Schengen" com a União Europeia, o exercício teórico em causa requereria a demonstração, que se fez, da existência do necessário paralelismo, para o efeito, entre a União Europeia e o Mercosul.

Uma sintética investigação sobre o "Espaço Schengen" permite concluir que o mesmo tem duas grandes finalidades: por um lado, contribuir para a efectivação prática da liberdade de circulação no seu âmbito; e, por outro lado, assegurar, também no seu interior e com igual nível de prioridade, um adequado grau de segurança.

Para a consecução da sobredita liberdade, veio proceder-se, em execução das competentes normas, à abolição dos controlos nas denomináveis fronteiras internas, ou seja, entre os Estados participantes no "Espaço Schengen". E, para a consecução da supramencionada segurança, vieram reforçar-se também, nos competentes termos normativos, os controlos nas denomináveis fronteiras externas, vale dizer, no conjunto das fronteiras nacionais simultaneamente delimitadoras do próprio "Espaço Schengen". Em complemento daquelas medidas fundamentais, e ainda no intuito de garantir um adequado grau de segurança no seu interior, a regulamentação do "Espaço Schengen" veio contemplar outros temas, como a atribuição de vistos, a concessão de asilo, o estatuto dos refugiados, a elaboração duma lista de pessoas indicadas para efeitos de não admissão no espaço, a cooperação policial, e a feitura e manutenção dum sistema de informações. 
Ora, tendo em conta as características do Mercosul, que aspira à criação dum mercado comum e foi concebido tendo como modelo de referência o percurso da integração europeia, tem sentido questionar se seria teoricamente aconselhável, ou desaconselhável, uma "transposição" do mecanismo do "Espaço Schengen" (ancorado na União Europeia) para o âmbito da integração plasmada no Mercosul. E torna-se indispensável, para responder à questão assim colocada, proceder à análise duma série de ingredientes, cuja consideração permitirá recolher os elementos necessários à formulação dum juízo sobre a desejabilidade, ou não, do lançamento, no âmbito do Mercosul, duma experiência paralela à do "Espaço Schengen".

Nos citados ingredientes cabem: o nível existente de confiança entre os Estados participantes; o nível existente de nacionalismos no seio dos mesmos (designadamente manifestados sob a forma de questões de fronteiras); o nível de estabilidade política reinante entre os Estados envolvidos; o nível de capacidade económica dos Estados intervenientes; o nível de homogeneidade verificado entre os Estados componentes; o nível de entendimento logrado, relativamente às questões financeiras, entre os Estados participantes; a natureza das zonas envolventes do eventual "Espaço", designadamente em termos de estabilidade ou instabilidade política, bem como da existência ou inexistência de pressões migratórias rumo ao interior do "Espaço"; e o nível de probabilidade do surgimento, ou não, de problemas de corrupção em Estados intervenientes, sobretudo da corrupção sistemática ou ligada ao crime transnacional organizado.

A curta análise efectuada aos diversos ingredientes elencados permite concluir pela impossibilidade de extrair, num plano apriorístico, conclusões inequívocas ou categóricas, relativamente ao tema que nos ocupou, dado tais ingredientes apontarem, naquele plano, em sentidos nem sempre coincidentes. Caso se pretenda a obtenção duma resposta peremptória, haverá pois que buscála num contexto também peremptório, vale dizer, na circunstância, delimitado pelo que concerne ao respectivo momento temporal e no tocante aos potenciais Estados envolvidos.

\section{REFERENCIAS}

ALMEIDA, Paulo Roberto de: O Brasil e o futuro do Mercosul: dilemas e opções. In: BORBA CASELLA, P. (Dir.): Mercosul: integração regional e globalização. Rio de Janeiro, Renovar, 2000. p. 13-38. 
BRADY, Hugo. Saving Schengen: how to protect passport-free travel in Europe. Centre for European Reform, 2012. Disponivel em: $<$ http:// www.cer.org.uk/sites/ default/files/publications/attachments/pdf/2012/ rp_041_km-6422.pdf>. Acesso em: 15 set. 2013.

COMUNIDADES EUROPEIAS. Acórdão do Tribunal de Justiça, de 13 de dezembro de 1989. Corsica Ferries France /Direction générale des douanes. Proc. C-49/89. Colectânea da Jurisprudência do Tribunal (versão portuguesa). 1989. p. 4441 ss. considerando $\mathrm{n}^{\mathrm{o}} 8$, p.4456.

COMUNIDADES EUROPEIAS. Acórdão do Tribunal de Justiça, de 5 de Maio de 1982. Schul / Inspector dos Direitos de Importação e dos Impostos de Consumo. Proc. 15/81. Raccolta della Giurisprudenza della Corte (versão italiana). 1982. p.1409 ss.

CEIA, Eleonora Mesquita: How can Brazil's leading Role in South America contribute to boosting Security Cooperation between the EU and Mercosur?, Observatori de Politica Exterior Europea: Working Papers $O B S$, July 2008, no 78, consultado em 16 de Setembro de 2013.

Disponível em: $<$ http://www.iuee.eu/pdf-publicacio/146/

fMC5iPFzMjT4hNolO5VP.PDF>. Acesso em: 10 abr. 2013.

FRERES, Christian; SANAHUJA, José Antonio. Hacia una nueva estrategia en las relaciones Unión Europea- América Latina. In: FRERES, Ch.; Sanahuja, J. A. (Coord.). América Latina y la Unión Europea: estrategias para una asociación necesaria. Barcelona: Icaria, 2006.

PARKES, Roderick: Punitive European Policy: a view from the North. Notes internacionals CIDOB, n. 30, May 2011. Disponível em: $<$ http:// www.cidob.org/ en/content/download/26790/324252/file/ NOTES+30_PARKES.pdf>. Acesso em: 15 set. 2013.

PASCOUAU, Yves. Schengen Area under Pressure: controversial responses and worrying Signs. EPC Commentaries, 3 may 2011a. Disponível em: <http:/www.epc.eu/documents/uploads/pub_1270_schengen_area_ under_pressure_-_controversial_responses_and_worrying_signs.pdf $>$. Acesso em: 15 set. 2013. 
PASCOUAU, Yves. Schengen Area under Pressure \# 2: the Commission recalls the EU nature of the Schengen system, EPC Commentaries, 10 may 2011b. Disponível em: $<$ http://www.epc.eu/documents/uploads/ pub_1275_schengen2.pdf $>$ Acesso em: 15 set. 2013.

PATRÍCIO, Raquel Cristina de Caria: As Relações em Eixo francoalemãs e as Relações em Eixo argentino-brasileiras: génese dos processos de integração, tese de doutoramento. Lisboa: Instituto Superior de Ciências Sociais e Políticas, 2007.

PIZZOLO, Calogero. Globalización e integración: ensayo de una teoría general: Comunidad Andina, Mercosur, Unión Europea, SICA. Buenos Aires: EDIAR, 2002.

SÁNCHEZ, Alberto M. Derecho de la integración: un recorrido múltiple por las experiencias de la Unión Europea y del Mercosur. Buenos Aires: RAP, 2004.

WOLKMER, Antonio Carlos. Integração e Direito Comunitário LatinoAmericano. In: PIMENTEL, L. O. (Org.). Mercosul no cenário internacional: Direito e Sociedade. Curitiba: Juruá, 1998. p.43-54.

ZAIOTTI, Ruben: The Beginning of the End? The Italo-French Row over Schengen and the Lessons of Past 'Crises' for the Future of Border Free Europe. EUCE Occasional Papers, June 2011, n. 12. Disponível em: $<$ http:// www.academia.edu/ 1591178/_The_Beginning_of_the_End_The_ItaloFrench_Row_over_Schengen_ and the_Lessons_of_Past_Crises_for_the_Future_of_Border_Free_Europe $>$. Acesso em: 15 set. 2013.

Artigo recebido em 22/09/13 e Aprovado para publicação em 12/11/13

Como citar: LAUREANO, Abel; RENTO, Altina. Poderá o "Espaço Schengen" Europeu servir como uma espécie de "laboratório de análise" para o Mercosul?. Scientia Iuris, Londrina, v.17, n.2, p.131-148, dez.2013. DOI: $10.5433 / 2178-8189.2013 v 17 \mathrm{n} 2 \mathrm{p} 131$. 